\title{
ALFRED DE MUSSET, Un Spectacle dans un fauteuil. La Coupe et les Lèvres, À quoi rêvent les jeunes filles, Namouna
}

\section{Valentina Ponzetto}

\section{(2) OpenEdition}

\section{Journals}

Édition électronique

URL : https://journals.openedition.org/studifrancesi/22991

DOI : 10.4000/studifrancesi.22991

ISSN : 2421-5856

Éditeur

Rosenberg \& Sellier

\section{Édition imprimée}

Date de publication : 1 avril 2020

Pagination : 200-201

ISSN : 0039-2944

\section{Référence électronique}

Valentina Ponzetto, " ALFREd de musset, Un Spectacle dans un fauteuil. La Coupe et les Lèvres, À quoi rêvent les jeunes filles, Namouna », Studi Francesi [En ligne], 190 (LXIV | I) | 2020, mis en ligne le 01 mai 2020, consulté le 03 août 2021. URL : http://journals.openedition.org/studifrancesi/22991 ; DOI : https:// doi.org/10.4000/studifrancesi.22991

Ce document a été généré automatiquement le 3 août 2021

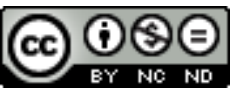

Studi Francesi è distribuita con Licenza Creative Commons Attribuzione - Non commerciale - Non opere derivate 4.0 Internazionale. 


\title{
ALFRED DE MUSSET, Un Spectacle dans un fauteuil. La Coupe et les Lèvres, À quoi rêvent les jeunes filles, Namouna
}

\author{
Valentina Ponzetto
}

\section{RÉFÉRENCE}

ALFRED DE MUSSET, Un Spectacle dans un fauteuil. La Coupe et les Lèvres, À quoi rêvent les jeunes filles, Namouna, édition établie par S. Ledda, Paris, Gallimard, 2019, «Folio théâtre», $322 \mathrm{pp}$.

1 L'édition d'Un Spectacle dans un fauteuil, le premier, en vers, de 1832, vient enrichir la collection des nombreuses éditions de Musset procurées par Sylvain Ledda. Le volume, on le rappellera, comprend l'assemblage hétéroclite, fantaisiste et de prime abord surprenant de deux pièces de théatre «à lire», le «poème dramatique» de couleur byronienne ou schillérienne La Coupe et les lèvres et la comédie À quoi rêvent les jeunes filles, «où l'intelligence le dispute à la fantaisie» (p. 233), suivies du poème orientalisant Namouna et précédées d'une insolente et ironique Dédicace à l'ami dandy Alfred Tattet, morceau «faussement programmatique» qui ne délivre aucun précepte théâtral, mais où l'on pourra s'efforcer de lire en creux quelques bribes d'une théorie dramatique mussétienne (p.8), ou en tout cas une prise de position intellectuelle dans le débat littéraire du temps.

2 Contrairement aux traditions éditoriales plus consolidées, qui privilégient les dernières éditions parues du vivant de l'auteur, et suivant par contre l'exemple de Frank Lestringant (Poésies complètes, Livre de Poche, 2006), l'édition de référence retenue est ici la première, parue chez Renduel en 1832 (datée 1833). On ne saurait qu'adhérer à ce choix, étant donné que - Sylvain Ledda le rappelle - chez Musset «le premier jet est souvent le meilleur» (p.35) et que le relevé exhaustif des variantes du manuscrit 
Lovenjoul, transcrites par Maurice Allem (Gallimard, 1957), révèlent un jeune Musset «attentif au détail» et «perfectionniste» dans son processus de composition (p. 36).

Publier le recueil dans la collection «Folio théâtre» est un geste éditorial plus significatif qu'il n'y paraît. Contre une tradition qui inscrit le petit volume dans l'œuvre poétique de Musset, cela signifie en effet le revendiquer complètement comme appartenant au domaine du théâtre, quoiqu'éventuellement pour un seul spectateur, metteur en scène de son propre théâtre mental. «Musset lui fournit tous les éléments pour concevoir son spectacle: des personnages, un décor, une intrigue et même un hors-scène. La matérialité de la représentation peut ainsi rester en latence, ce qui ne signifie pas la négation du théâtre mais son intériorisation» (p. 14). Par logique conséquence de ce choix, l'intéressante «Notice» consacrée aux trois œuvres en fin de volume (pp. 233-257) adopte la structure habituelle pour les pièces de théatre (ce qui n'est généralement pas le cas pour ces textes): circonstances de compositions et sources d'inspiration (qui font la part belle à Shakespeare, Schiller, Goethe, mais aussi à Molière, Beaumarchais, Hugo et le Weber du Freischütz), réception critique, et historique de la mise en scène depuis la création. Cette dernière fut certes tardive et souvent médiée par une adaptation pour les trois textes, mais on rappellera que ce fut le cas aussi pour d'autres œuvres théâtrales de Musset, Lorenzaccio avant toutes. On découvre ainsi une fortune scénique plus riche qu'on ne penserait pour ces trois textes, $\mathrm{y}$ compris le poème Namouna qui rejoint la scène par le biais de la musique et de la danse, grâce à la Djamileh de Bizet (1871, sur un livret de Louis Gallet), et au ballet de 1882 (musique d'Edouard Lalo, chorégraphie de Lucien Petitpas), auquel la Suite en blanc de Serge Lifar a offert au xxe siècle un second souffle et un succès toujours de saison.

4 La préface est commune aux trois textes, et met donc en avant en premier lieux les deux pièces, même si les considérations sur la question de la vérité et du mensonge, ou pour mieux dire du mensonge révélateur, et celles sur la versification du recueil s'appliquent également à Namouna.

5 L'étude de la théâtralité du vers mussétien, ainsi que du rythme et de l'esthétique de la prosodie propres au Spectacle dans fauteuil représentent sans doute l'apport le plus original et le plus subtilement travaillé de cette édition. Sylvain Ledda étudie avec l'oreille exercée d'un fin connaisseur de Musset et d'un comédien la langue «tantôt âpre, tantôt légère, qui n'hésite pas à toucher au sublime» de ce recueil surprenant (p.16), ses couleurs sensuelles, qui donnent à voir l'univers évoqué comme des didascalies internes à la forte puissance picturale, son vers souvent haché par les cadratins, comme oralisé, variant les rythmes, les accents, les coupures et les modèles de sa palette (invocations, hymnes, élégies, stances, méditation, contemplations), ses rimes à peine suffisantes, accentuant l'effet de désinvolture, et produisant au final «une sorte de parlé-chanté, qui fait le charme du recueil» (p. 23).

6 Suit une étude des ressorts plus proprement théâtraux du recueil, menée d'abord à travers l'analyse du palimpseste de référents littéraires, mêlant l'ancien, par exemple le recours au chœur dans La Coupe ou à la comédie romanesque d'un autre siècle dans À quoi rêvent les jeunes filles, et le moderne, incarné principalement par des personnages profondément romantiques. Enfin l'étude du motif théâtral du masque et du déguisement pose le problème de la dichotomie mensonge-vérité, du dévoilement métaphysique et de la «vérité à soi-même». 
7 Sous tous ces aspects, le Spectacle dans un fauteuil de 1832 se révèle pleinement une excellente entrée dans l'univers mussétien et, comme le dit Sylvain Ledda, une «étape décisive dans la constitution de l'œuvre dramatique la plus originale du XIX ${ }^{e}$ siècle» 